\title{
Erratum to: Echoes of 2HDM inflation at the collider experiments
}

\author{
Tanmoy Modak ${ }^{1, \mathrm{a}} \mathbb{D}$, Kin-ya Oda ${ }^{2, \mathrm{~b}}$ \\ ${ }^{1}$ Institut für Theoretische Physik, Universität Heidelberg, Heidelberg 69120, Germany \\ ${ }^{2}$ Department of Physics, Osaka University, Toyonaka, Osaka 560-0043, Japan
}

Received: 25 May 2021 / Accepted: 28 May 2021 / Published online: 16 June 2021

(C) The Author(s) 2021

Erratum to: Eur. Phys. J. C (2020) 80:863

https://doi.org/10.1140/epjc/s10052-020-08450-5

The Fig. 1 of Ref. [1] is plotted for $\tilde{\eta}_{1}-\xi_{11}$ (left panel) and $\tilde{\eta}_{1}-\xi_{22}$ (right panel), which do not conform to the caption and the subsequent discussions in the text. We now present the $\eta_{\mathrm{eff}}-\xi_{11}$ and $\eta_{\mathrm{eff}}-\xi_{22}$ plots as shown in the Fig. 1.

\section{Reference}

1. T. Modak, K. Oda, Eur. Phys. J. C 80, 863 (2020). https://doi.org/ 10.1140/epjc/s10052-020-08450-5. arXiv:2007.08141 [hep-ph]
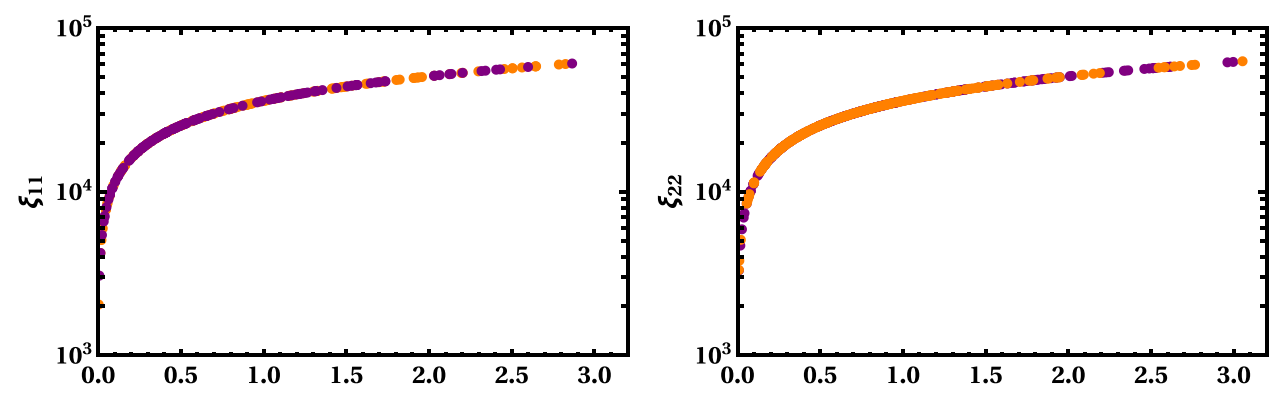

Fig. 1 The scanned points plotted for Scenario-I (Scenario-II) in $\eta_{\text {eff }}-\xi_{11}\left(\eta_{\text {eff }}-\xi_{22}\right)$ plane in the left panel (right panel) respectively. The purple and orange scanned points are respectively for $c_{\chi_{0}}=1$ and $c_{\chi_{0}}=-1$

Open Access This article is licensed under a Creative Commons Attribution 4.0 International License, which permits use, sharing, adaptation, distribution and reproduction in any medium or format, as long as you give appropriate credit to the original author(s) and the source, provide a link to the Creative Commons licence, and indicate if changes were made. The images or other third party material in this article are included in the article's Creative Commons licence, unless indicated otherwise in a credit line to the material. If material is not included in the article's Creative Commons licence and your intended use is not permitted by statutory regulation or exceeds the permitted use, you will need to obtain permission directly from the copyright holder. To view a copy of this licence, visit http://creativecomm ons.org/licenses/by/4.0/.

Funded by $\mathrm{SCOAP}^{3}$.

The original article can be found online at https://doi.org/10.1140/ epjc/s10052-020-08450-5.

a e-mail: tanmoyy@hep1.phys.ntu.edu.tw (corresponding author)

b e-mail: odakin@phys.sci.osaka-u.ac.jp 